\title{
Comparison of the effects of alclofenac, flurbiprofen, and prednisolone on acute inflammatory response in the rat
}

\author{
J. WOODLAND, B. VERNON-ROBERTS, K. V. SWETTENHAM, AND \\ H. L. F. CURREY
}

From the Bone and Joint Research Unit, The London Hospital, London E1 1 BB

SUMMARY The fluid and cellular phases of the inflammatory response were measured using? technique employing subcutaneous implantation of polyurethane foam cubes impregnated with heat-killed Mycobacterium tuberculosis. Flurbiprofen and prednisolone were equipotent and wege capable of almost completely suppressing fluid and cellular responses, while alclofenac was less potent at nontoxic dose levels. Study of the patterns of cellular exudation by image analysipty computer showed that alclofenac appears unique in that it produces a well-defined cell-free zome between the edge of the implanted cubes and a band of neutrophil polymorphs within the cubes.

A model for studying the anti-inflammatory action of drugs in the rat has been developed in this laboratory (Clarke et al., 1975) using the subcutaneous implantation of polyurethane cubes impregnated with an irritant. When removed 5 days after implantation, the cubes can be analysed separately for the protein content of the fluid exudate and for cellular exudation. Using this method to test a variety of drugs used in the treatment of rheumatoid arthritis, we showed that aspirin, phenylbutazone, sodium aurothiomalate, hydroxychloroquine, Dpenicillamine, azathioprine, cyclophosphamide, and prednisolone were all capable of suppressing cellular exudation in an acute inflammatory response induced by dead tubercle bacilli. However, unlike the other drugs investigated, sodium aurothiomalate, hydroxychloroquine, and D-penicillamine were incapable of suppressing protein exudation under the same experimental conditions.

The findings suggested the possibility that the model might provide a basis for categorizing drugs according to their mode of action in rheumatoid arthritis. For this reason we have now used the same test system to investigate alclofenac, a drug for which there have been claims that it may have a delayed effect in rheumatoid arthritis (Aylward et al., 1975) similar to that of sodium aurothiomalate and D-penicillamine. We have also investigated flurbi-

Accepted for publication July 27, 1976 Correspondence to Prof. H. L. F. Currey profen, at present being developed as a new ani inflammatory and analgesic agent. The effects 尹f $^{\prime}$ both drugs have been compared with prednisolo ge, a known potent anti-inflammatory drug.

\section{Materials and methods}

Sprague-Dawley rats weighing $250-300 \mathrm{~g}$ were used throughout. The preparation, implantation, apd processing of the polyurethane foam cubes followed the procedure described previously (Clarke et dis., 1975). Each cube weighing $17 \mathrm{mg}$ was impregnatêd with a suspension of heat-killed Myco. tuberculosis (approximately $0.3 \mathrm{mg}$ dry organisms per cube) and dried and sterilized before implantation. Four sugh cubes were implanted subcutaneously at separate sites into the flanks of each rat. The animals weire killed 5 days later and the cubes removed. All three drugs were administered as single daily doses from day 0 to day +4 . Suspensions of alclofenac and flurbiprofen in $0.25 \%$ carboxymethylcellulose wexe given by oral feeding tube, while prednisolone dessolved in arachis oil was injected intraperitonealdy. The doses used are shown in the Table. Control animals received comparable volumes of oral carboxymethylcellulose.

The protein content of the fluid exudate was found by drying the cubes to constant weight at 37\% and measuring the dry weight gain in excess of initial $17 \mathrm{mg}$ accounted for by the weight of the cube itself. 
Table Effect of prednisolone, flurbiprofen, and alclofenac on dry weight gain and depth of cell infiltration in polyurethane cubes impregnated with heat-killed Myco. tuberculosis

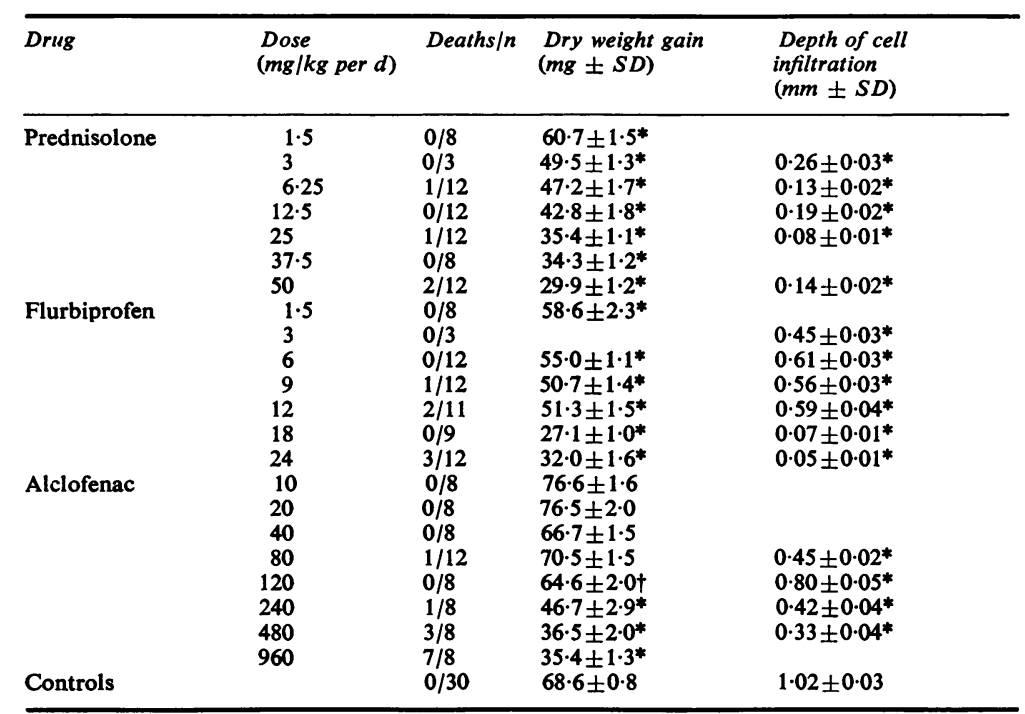

$+P>0.001 . \quad+P<0.05$.

Cellular exudation was assessed in two ways. (1) The depth of cellular infiltration into each cube was measured microscopically using an eyepiece graticule aligned at 10 positions around the periphery of $5 \mu \mathrm{m}$ thick haematoxylin and eosin stained sections. Two cubes were processed in this way from each animal. Differential cell counts were also performed. (2) The density of cellular infiltration was assessed using a Quantimet 720 Image Analysing Computer (Cambridge Instruments) coupled to a Hewlett Packard 9830A programmed calculator. In this system each field viewed in the microscope is scanned by a television camera and a rectangular portion of the field is displayed as a black-and-white image on a television screen. The image on the screen is made up of many small picture-points and, by adjusting the detection level, the number of picturepoints making up specific features in the image of selected areas of the microscope field can be computed. The image analyser can therefore measure the area occupied by selected features in the microscope field.

In this study we examined $5 \mu \mathrm{m}$ sections of cubes which had been stained by the Feulgen technique to show nuclear DNA, and the detection level of the image analyser was adjusted to detect Feulgenpositive material alone. The profile of cell density was measured by examining the area occupied by Feulgen-positive material in each of eight sequential microscope fields from the periphery to the centre of cubes at $\times 10$ objective magnification; thus, each individual field covered a distance of $600 \mu \mathrm{m}$ in width. The mean profile of cell density for each dose level was calculated from ten such sequential measuring operations at randomly selected areas of different cubes. The overall shapes of the profiles of cell density in separate cubes were remarkably consistent and reproducible at each dose level, so that the mean of 10 such profiles for each dose level reflects the pattern of cell density both quantitatively and qualitatively.

\section{Results}

\section{PROTEIN CONTENT OF FLUID EXUDATE}

(TABLE, FIG. 1 $a$ )

A dry weight gain of about $30 \mathrm{mg}$ represents complete suppression of fluid exudation in the inflammatory response attributable to the tubercle bacilli in the cubes. This degree of suppression was achieved by both prednisolone and flurbiprofen at dosage levels which produced few deaths among the animals, but in the case of alclofenac it was achieved only with doses which killed many of the animals. In terms of relative potency the dose-response line for alclofenac shows it to occupy approximately the same position as aspirin did in the previous studies, while, impressively, flurbiprofen is equipotent with prednisolone. 


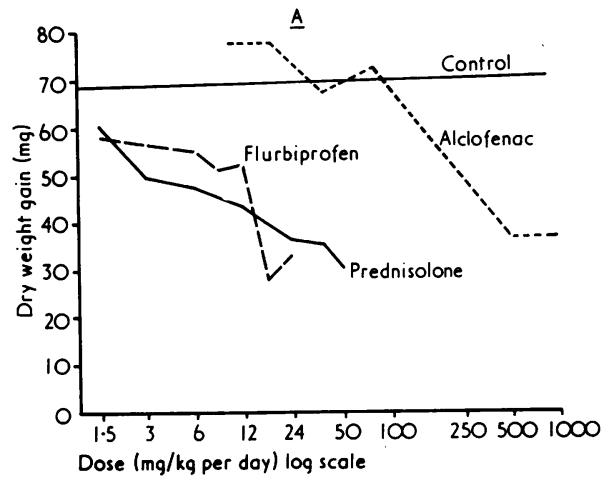

not reflected in this simple depth measurement. particular, certain doses of alclofenac appeared have produced a relatively cell-free area at the periphery of the cube, while leaving a dense infiltrate more deeply situated (Fig. $2 b, c$ ). For this reason image analysing computer was used to study the pattern of cell density in the cubes.
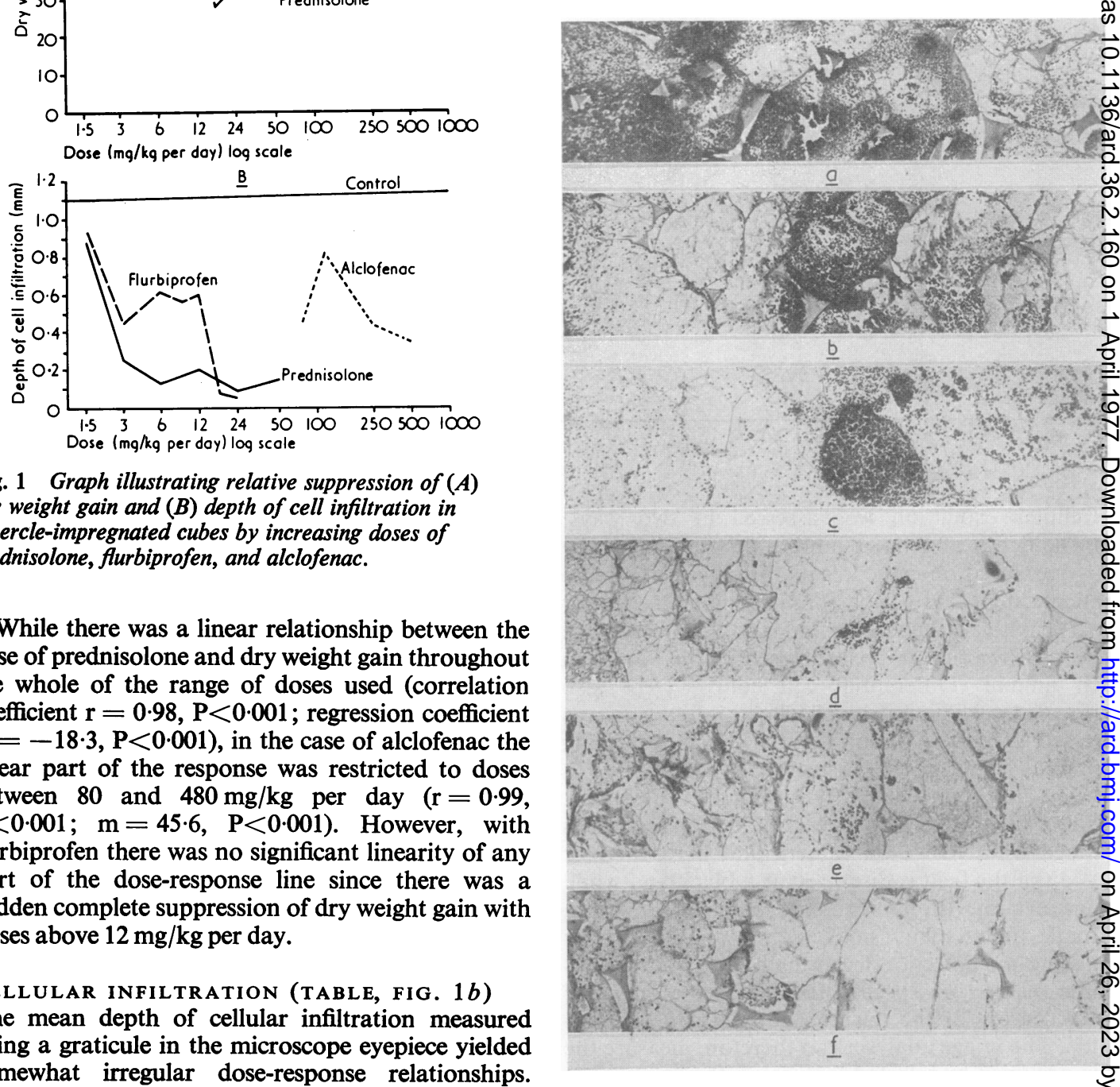

Fig. 1 Graph illustrating relative suppression of $(A)$ dry weight gain and $(B)$ depth of cell infiltration in tubercle-impregnated cubes by increasing doses of prednisolone, flurbiprofen, and alclofenac.

While there was a linear relationship between the dose of prednisolone and dry weight gain throughout the whole of the range of doses used (correlation coefficient $r=0.98, P<0.001$; regression coefficient $\mathrm{m}=-18.3, \mathrm{P}<0.001$ ), in the case of alclofenac the linear part of the response was restricted to doses between 80 and $480 \mathrm{mg} / \mathrm{kg}$ per day $(\mathrm{r}=0.99$, $\mathrm{P}<0.001 ; \mathrm{m}=45.6, \mathrm{P}<0.001)$. However, with flurbiprofen there was no significant linearity of any part of the dose-response line since there was a sudden complete suppression of dry weight gain with doses above $12 \mathrm{mg} / \mathrm{kg}$ per day.

Cellular infiltration (TABLe, Fig. $1 b$ )

The mean depth of cellular infiltration measured using a graticule in the microscope eyepiece yielded somewhat irregular dose-response relationships. However, all three drugs did suppress cellular infiltration, alclofenac being less potent than the other two and approximately equivalent to phenylbutazone in our previous studies.

There was close agreement about the overall depth of cellular infiltration measured by different observers on separate occasions. The distribution and density of the cells within the infiltrate however indicated differences between the treatment groups

Fig. 2 Photomicrographs of representative areas of cubes scanned by image analyser. The outer edge of eact cube is on the left and the centre to the right. These show the pattern of cell infiltration in (a) control rats, and in rats treated with (b) alclofenac $120 \mathrm{mg} / \mathrm{kg}$; (c) alclofenac $240 \mathrm{mg} / \mathrm{kg}$; (d) alclofenac $480 \mathrm{mg} / \mathrm{kg}$; (e) prednisolone $50 \mathrm{mg} / \mathrm{kg}$; and $(f)$ flurbiprofen $18 \mathrm{mg} / \mathrm{kg}$. Note the relatively cell-free zone near the edge of the cube in $(b)$ and $(c)$, and the absence of cells in $(d),(e)$, and $(f)$. Haematoxylin-eosin. $\times 25$. 
PATTERN OF CELL DENSITY (FIGS. 2, 3)

In the control rats, microscope examination of sections of cubes impregnated with dead tubercle bacilli and removed 5 days after subcutaneous implantation showed the presence of a cellular infiltrate which was most dense at the periphery of the cube and progressively less dense towards its centre (Fig. 2a). The cells of this infiltrate comprised

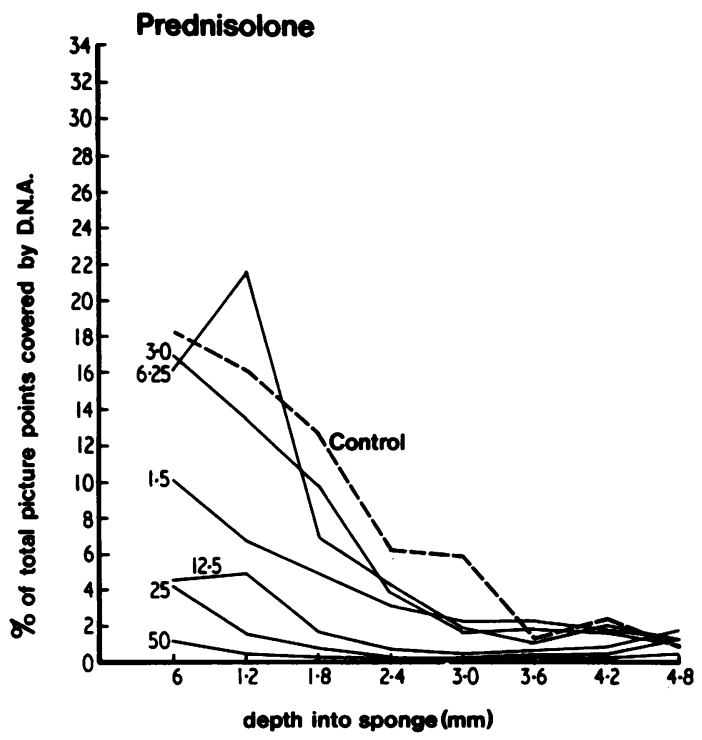

(a)

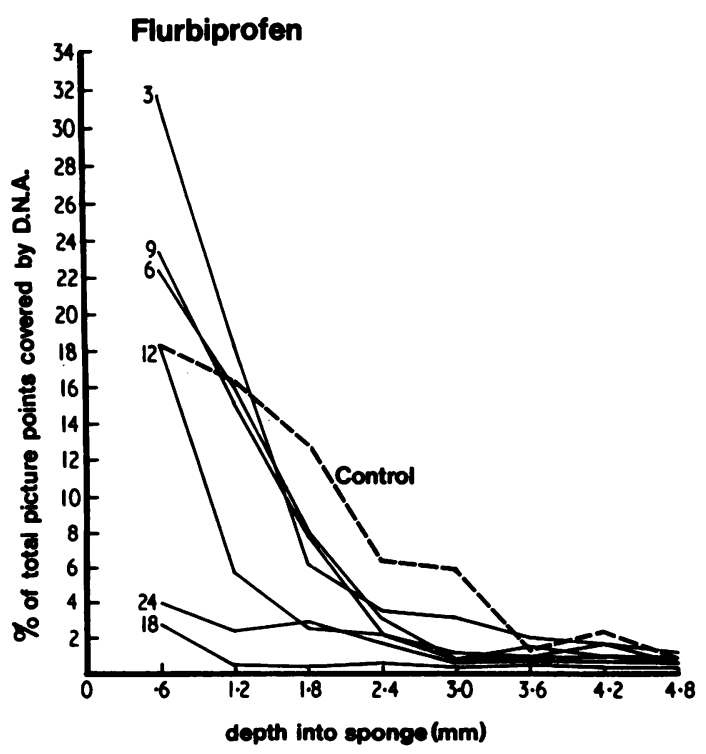

(b) about $95 \%$ neutrophil polymorphs and $5 \%$ macrophages. Image analysis confirmed that there was a progressive diminution of the area (and therefore the volume) of the cube section occupied by nuclear DNA away from the periphery of the cubes in the control animals (Fig. 3), about $20 \%$ of the cube being occupied by nuclear DNA at the periphery and falling progressively to less than $2 \%$ at a distance of $3.6 \mathrm{~mm}$ into the cube.

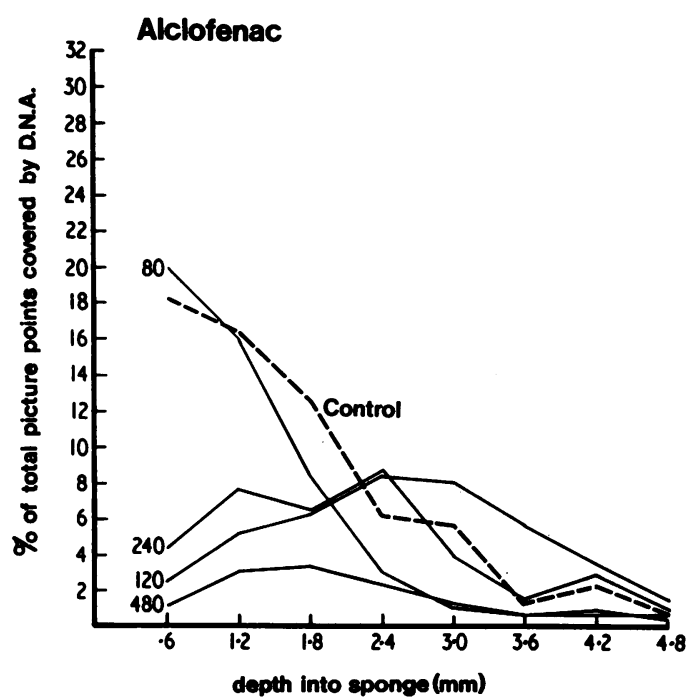

(c)

Fig. 3 Percentage areas occupied by the nuclear DNA of infiltrating inflammatory cells at varying depths into cubes after treatment with (a) prednisolone, (b) furbiprofen, and (c) alclofenac.

Treatment with prednisolone in doses in excess of $12.5 \mathrm{mg} / \mathrm{kg}$ per day caused a marked reduction in cell infiltration and cell density so that less than $5 \%$ of the cube was occupied by nuclear DNA even at the periphery (Fig. 3c). With doses of prednisolone between 1.5 and $6.25 \mathrm{mg} / \mathrm{kg}$ per day it was found that the lower doses were more effective than the higher in reducing cell density in the peripheral $2.4 \mathrm{~mm}$ of the cube (Fig. $3 a$ ). Moreover, at a dose of $6.25 \mathrm{mg} / \mathrm{kg}$ per day, the presence of a zone of loose granulation tissue at the periphery of the cube resulted in lower cell density in this region.

Flurbiprofen in doses of $18-24 \mathrm{mg} / \mathrm{kg}$ per day produced the same marked reduction of cell density (Fig. $3 b$ ) as did the highest doses of prednisolone. However, at doses of $3-9 \mathrm{mg} / \mathrm{kg}$ per day there was an increase in cell density in the peripheral $1.2 \mathrm{~mm}$ of the cube when compared with the control cubes (Fig. $3 b$ ), but with suppression of cell density below 
control level beyond this distance. In the case of these lower doses of flurbiprofen the increased cell density was due to the presence of increased numbers of neutrophil polymorphs at the periphery of each cube.

When alclofenac was given in doses of 120 and $240 \mathrm{mg} / \mathrm{kg}$ per day an interesting phenomenon was observed: cell density was reduced to below $5 \%$ at the periphery, but increased to join the control curve at about $2.5 \mathrm{~mm}$ into the cube (Fig. 3c). At 480 $\mathrm{mg} / \mathrm{kg}$ per day there was an overall reduction in cellular infiltration, although the cell density was again greater at some distance from the periphery (Fig. 3c). Microscopy showed that the low cell density at the periphery of the cubes with doses of alclofenac between 120 and $480 \mathrm{mg} / \mathrm{kg}$ per day was due to the presence of a relatively cell-free zone at the periphery, containing scattered macrophages, between the edge of the cube and the neutrophil-rich exudate (Fig. $2 b, c, d$ ).

\section{Discussion}

The results obtained in these experiments have to be viewed in the light of our previous experience with this acute inflammatory model (Clarke et al., 1975). Flurbiprofen is one of a series of new anti-inflammatory and analgesic agents developed with the object of producing a more potent but less toxic drug for use in conditions such as rheumatoid arthritis. The findings presented here show flurbiprofen to be extremely potent in this rat antiinflammatory assay, such that it is capable of suppressing the protein content of the fluid exudate and cellular exudation to the same extent, and in the same dosage range, as prednisolone. This confirms the potency of this preparation in other models of inflammation in rodents reported by Adams et al. (1975) and by Ishii et al. (1975).

Alclofenac was studied because of the recent claim (Aylward et al., 1975) that it may exert a delayed effect in rheumatoid arthritis, possibly similar to that of sodium aurothiomalate, chloroquine, and D-penicillamine-the three drugs which in our previous study using this assay system (Clarke et al., 1975) were found to suppress cellular infiltration into the tubercle-impregnated cubes in doses which did not influence the protein content of the fluid exudate. In fact, in the present studies alclofenac appeared to inhibit both cellular and fluid exudation in approximately the same dosage range (although studies of the density of cellular exudation provided evidence that alclofenac influenced this parameter in an unusual way-see below). It is possible that alclofenac (like the 'immunosuppressive' agents) is anti-inflammatory in addition to any 'delayed' effect it may have in rheumatoid arthritis. Alclofenac was considerab less potent than the other two drugs tested.

In the present study we have used an image analysing computer to carry out a preliminary study of the distribution of cellular exudation. This hes proved to be a much more sensitive and less subje tive indicator of the intensity and extent of cellular exudation than the method of measuring the overăl 'depth' of the cellular infiltrate microscopically wi a graticule eyepiece. Various interesting findings have emerged from this study of cellular exudatiggt by image analysis.

(1) Flurbiprofen was impressively equipotent with the higher doses of prednisolone in suppressicos cellular exudation, and both drugs were capable of producing an almost complete absence of inflare matory cells in the cubes. (2) With doses of predngsolone below $6.25 \mathrm{mg} / \mathrm{kg}$ per day, the lower doses were more effective than the higher in suppressing cellular exudation. The reason for this is obscure but it is consistent with previous findings that low doses of corticosteroids stimulate macrophage phagocy activity and an increase of inflammatory exudate (Nicol et al., 1965, 1967). (3) Low doses of flurbf profen increased the density of inflammatory cels in the peripheral margin of the implanted cubes b reduced the extent to which cells entered the cubsts beyond this point. This could be interpreted showing that low doses of flurbiprofen are unable to prevent the migration of inflammatory cells through the walls of blood vessels at the inflammatory site (i.e. do not affect vascular permeability to cells), but at the same time the chemotactic migration of the cells deeper into the inflammatory site is inhibite $\bar{\phi}$ (4) Alclofenac results in the formation of a rele tively cell-free zone between the edge of the implanted cubes and a band of neutrophil polymorphs with the cubes. One explanation for this interesting phenomenon could be that the inflammatory cels initially migrate into the cubes to the same extent in the untreated control animals, but that alclofenac exerts its anti-inflammatory action in a delayed manner so that the migration of the cells which would normally follow the initial influx are su\& pressed (i.e. there is a delayed inhibition of exuda tion). Alternatively, alclofenac could conceivab exert a direct toxic effect on neutrophil polymorpho so that the cells at the periphery of the cubes, being exposed to the higher concentrations of the drug, die to produce the cell-free zone. It is clear that furthef studies will be needed to clarify this phenomenon.

To our knowledge this is the first time that image analysis has been applied to the study of inflanis matory exudates, and the findings show that the patterns of cellular exudation are far from uniform 
when influenced by drugs and that dose-related phenomena occur with individual drugs. The findings could provide useful pointers to the mechanism of action of anti-inflammatory agents. From a practical point of view it highlights the fact that in assay models of this type, a simple measure of the depth of cellular infiltration is probably not an adequate indication of the effect of drugs on the cellular component of the inflammatory reaction. In this regard we intend to develop the use of the image analysing computer as an objective means of recording the patterns of cellular infiltration in inflammatory sites.

Our interest in the cube implantation model is now extending to the use of cubes impregnated with tubercular protein (PPD) in rats previously sensitized with Freund's complete adjuvant. There are already indications that this may allow us to detect drug effects not apparent when an irritant as powerful as whole dead tubercle bacilli is used. It will be of interest to examine whether the unusual pattern of cellular exudation produced by alclofenac can be detected when this less irritant immunological stimulus is used.

We are grateful to the Arthritis and Rheumatism Council for their support, and to the Medical
Research Council for a grant to purchase the image analysing computer.

\section{References}

Adams, S. S., McCullough, K. F., and Nicholson, J. S. (1975). Some biological properties of flurbiprofen, an antiflammatory, analgesic and antipyretic agent. ArzneimittelForschung, 25, 3-8.

Aylward, M., Parker, R. J., Holly, F., Maddock, J., and Davies, D. B. S. (1975). Long-term study of indomethacin and alclofenac in treatment of rheumatoid arthritis. British Medical Journal, 2, 7-9.

Clarke, A. K., Vernon-Roberts, B., and Currey, H. L. F. (1975). Assessment of anti-inflammatory drugs in the rat using subcutaneous implants of polyurethane foam impregnated with dead tubercle bacilli. Annals of the Rheumatic Diseases, 34, 326-331.

Ishii, Y., Sakai, Y., Masumoto, S., Inoue, M., Fujii, T., and Kobayashi, H. (1975). Absorption, distribution, excretion and anti-inflammatory effects of flurbiprofen in animals after rectal administration. Current Medical Research and Opinion, 3, Suppl. 4, 31-38.

Nicol, T, Vernon-Roberts, B , and Quantock, D. C. (1965). The influence of various hormones on the reticuloendothelial system: endocrine control of body defence. Journal of Endocrinology, 33, 365-383.

Nicol, T, Quantock, D. C., and Vernon-Roberts, B (1967). The effects of steroid hormones on local and general reticulo-endothelial activity: relation of steroid structure to function. Advances in Experimental Biology and Medicine, The Reticulo-endothelial System and Atherosclerosis, Vol. 1, p. 221. Ed. by N. R. DiLuzic and P. Paoletti. Plenum Press, New York. 